\title{
ON SOME OF THE MENTAL MECHANISMS IN DEMENTIA PRÆCOX*
}

\author{
BY AUGUST HOCH, M.D.
}

\section{Psychiatric Institute, New York State Hospitals}

$I^{\mathrm{N}}$

$\mathrm{N}$ this symposium I have been asked to take up the symptomatology of dementia præcox from the point of view of the content of the psychosis. It is, therefore, not within my province to dwell either on the general principles of the disorder, or the constitutional factors which play such an important part in these cases. $\dagger$ My task is rather to state briefly what a study of the content of the psychosis seems to indicate.

In certain simple paranoic states, or in a certain type of psychoses of degenerates to which Birnbaumf has recently devoted a monograph, it can scarcely be questioned that the content of the psychosis represents conflicts and reactions to conflicts which the individual, owing to an inherent constitutional deficiency, has been incapable of handling adequately. In cases in which we are able to analyze the symptom picture of dementia præcox we find a similar situation. While an outside view of dementia præcox reveals an arbitrary array of manifestations: of delusions, hallucinations, queer notions, or autochthonous ideas, an emotional condition often out of harmony with what the patient says, peculiar incoherent utterances which impress one merely as a scattered ideation, bizarre acts often executed with an impulsiveness which appears strikingly forced and elementary - an analysis often shows us that instead of there being a lack of connection or significance in this array of manifestations, all these expressions mean something to the patient, that definite principles of depen-

*Read as a part of the Symposium on Dementia Præcox at the meeting of the American Neurological Association, held in Washington, May, 1910.

† See Hoch, A. Constitutional Factors in the Dementia Præcox Group, Review of Neurology and Psychiatry, August, 1910.

$\ddagger$ Birnbaum. Psychosen mit Wahnbildung und wahnhafte Einbildunger bei Degenerativen. Carl Marhold, Halle, 1908. 
dence of the individual symptoms upon each other can be made out, that certain mechanisms are at work, and that instead of an arbitrary diffusion there is in these manifestations a certain limitation to definite trends. There are cases, therefore, in which the same principles exist as in some paranoic states and in some degenerative psychoses. The question is only how general an application may we claim for this. It is not easy to analyze cases of dementia præcox, and a satisfactory demonstration has been possible in a limited number of instances only, yet aside from those we have many examples in which more or less clear indications point in the same direction, to say nothing of the support which such a view receives from other sources, namely from the general principles as claimed by Dr. Meyer, and from the recognition of constitutional deficiencies which forms an integral part of these principles. On the other hand, it must be frankly admitted that there are still many gaps, and that a growing knowledge of the clinical pictures, with perhaps a clearer separation of cases into smaller groups, may also demonstrate that mechanisms of another sort are at work. The reason the situation is clearer in some paranoic and degenerative psychoses, and why, therefore, in them the psychogenic origin is not doubted, is because there the conflicts are on the surface, they often lie essentially in an external situation, whereas in dementia præcox the external factors are insignificant compared with the internal conflicts. We are, therefore, in dementia præcox dealing with undercurrents which, however, as our experience shows, seem to give rise to the same sort of attempts at adjustment as those conflicts which are more on the surface, but they are often less transparent, the conflicts less obvious, partly because the normal person cannot understand the opposing forces of the conflicts and the real desires, partly because they refer to very personal matters, and therefore are under the influence of distorting and repressing forces which make the analysis more difficult. Any one who has analyzed cases of dementia præcox must have been impressed with the fact that the content often unmistakably refers to disharmonies in the sexual sphere, and this is, as we have reason to believe, not accidental, 
but due to a fundamental defect of sexual adaptation in its widest sense.

I need hardly say in this audience that it is essentially Freud and Jung to whom we owe our insight into these principles, which are at times more clearly in evidençe in dementia præcox than in hysteria, though not fundamentally different from those of the neuroses and of every-day life. I propose to take up the subject by giving: (1) the analysis of a case who evidentally, owing to the comparatively good mental makeup, was particularly accessible, and who, probably for the same reason, eventually recovered; (2) the analysis of another case who did not recover; and (3) a brief general description of some of the more obvious mechanisms with which we are as yet acquainted, without any claim to completeness, even so far as our present knowledge goes.

The first case is that of a young girl of seventeen, who when seen presented a certain amount of excitement; yet without real distress, she tried the doors, made peculiar statements. She said that some one was in distress, that the country was in trouble, that she was "the center of a good deal." She spoke of explosions and automobile accidents, of fires, and the like,- - events of which she had learned from headlines in the newspapers which were lying about; but she did not blame herself for it, as melancholics would. She spoke of electricity being applied to her, said that she felt connected in some way; she heard voices which said, "Stand still," "Get up," "Look out," "Danger." She suddenly saw "a fog" and in it a railroad train and a face. She often would not go to bed, and, without being able to explain it, would violently oppose any attempt at putting her to bed. At other times she would not eat, would not pass her urine, was very insistent that some special patients in the ward should not be there. She often asked what things meant, in fact to anything which was at all obtrusive a feeling of self-reference was attached. She slept poorly and ate insufficiently. She was always oriented as to her surroundings. The patient presented, therefore, a peculiar impulsive behavior, which was never accounted for by the situation, nor by any obvious ideas; 
a markedly negativistic attitude at times, hallucinations in the form of voices, electricity, and occasionally visions; ideas of reference, odd acts, the whole characterized by a peculiar lack of transparency and want of connection.

The anamnesis told us that the patient had been selfwilled, pedantic, with a great desire for consistency and justice; she was ashamed of her menstruation, but withal fairly natural. At six a boy had intercourse with her, and threatened her if she told about it. She claims she did not think much of it. At about the age of ten she began to masturbate and worried much about this. When eleven, she one morning woke up frightened and saw Christ on the cross. The night before she had sat at the window listening to men who went by, wondering who they were and whether she would ever meet them. She does not remember any other fancies at the time. In the morning after the vision she worried about her masturbation, and then the episode at the age of six came to her mind and she confessed it to her grandmother. When thirteen and fourteen she used to sit more often at the window at night, losing much sleep thereby, dreaming in the same way as when she was eleven. It is probable - but we can only infer it - that sexual fancies occurred at that time. She worked normally until fifteen, when she became absorbed, could not do her work, and half a year later dropped it all. She was sent to a relative, the place where she had lived when six; she became worse, surprised her people by saying that she was in love with a man whom she scarcely knew; she kept watching the house of a physician whom she also knew but superficially, thought of him a good deal, as she confessed later; she claimed she saw another man, whom she had seen at her own home, pass daily on a train, saying she recognized him only by his hat. When again at home, near the sea, she saw searchlights, and thought the doctor above mentioned was "in distress," saw a vapor with his face in it. When taken to her family doctor there were two men in his waiting room; she thought they were there to tell the doctor of her masturbation, or about her love for the other physician; she also felt that one of the men was exerting electrical influences upon her. In a shoe store she thought she re- 
cognized the man who passed on the train, and the shoes she bought she never could wear because they were "charged with electricity." Finally, when she was again sent to the same relatives, she at once became more markedly abnormal, spoke of wires being through the house, of being surrounded by electricity, she refused food, hesitated to pass her urine, wanted things "straightened out," was undecided, and suddenly claimed she was married.

This patient could be analyzed even during the active stage of her condition, as it was found that she always quieted down when this was done. In the analysis many of the facts which have been embodied in the history were obtained, as well as the following:

It became clear that the idea of electricity represented a very important part of the picture and furnished the key to the situation. She said that electricity was tried in a way that it should not be tried, and said in the same connection that some one was trying to be near her, and finally that different people were trying to marry her, or were trying something which she did not wish to have tried. At last it was found that the electricity was localized in her sexual organs, and that the sensations were quite unlike electricity, but like the feeling which she had perceived during the sexual traumatism in the sixth year. This explained, then, the meaning of these sensations. And then the idea that she felt the electricity in the shoe store, and that the shoes were later charged with electricity, also became comprehensible. Moreover, it was found that these sexual sensations increased when she remained in certain positions for any length of time; hence she heard warning voices, saying "Stand up," "Look out"; they were most pronounced in bed; hence she frequently refused to go to bed, fought desperately when put there. The reason why she objected to the presence of certain patients became clear when it was found that all these were patients who wet their bed; that this, as she said, suggested to her kidney disease; the latter in turn suggested a vaginal examination, which her family physician had made, and this led, therefore, directly to the main trend. The refusal of food found its explanation partly in the fact that the sensations increased after 
eating, partly in that she had heard her family physician say at one time that meat increased the sexual desire. The voices, the idea that some one was in distress, etc., were invariably traced to one of the men mentioned in the history, and were probably also determined by a projection of her own distress.

I think, therefore, that the case resolves itself into this: we have here a girl who had an early concrete sexual experience. This very probably led her thoughts into the direction of sexual matters to a degree which evidently went beyond the normal tendencies of this sort - and more important to note is the fact that certain reactions all along showed that these fancies were evidently disturbing factors. She lost sleep sitting at the window wondering who the men were who went by, whether she would meet them, etc.; in this connection it is interesting that immediately after the first episode of this kind she woke up with fright and had a religious vision, and then worried about her masturbation and her earlier experience with the boy. Then the fact that she was ashamed of her menstruation is of interest, and her growing pedantry, her desire to have things right, may have been, as it often is, a reaction to the feeling of guilt about sexual ruminations.

Finally, there came an absorbed period which was so marked that any objective interest and activity became impossible. And then came that peculiar diffuse rather than specific application of her love to real persons, as is the case so frequently in dementia præcox, and which in itself points to the marked lack of sexual adaptation. She said she was in love with several men whom she merely knew from a distance, and thought she saw them in various places.

Now it is very natural that the original and only sexual experience played a part in her fancies, and when these became dominant the sensations connected with it were represented by hallucinations; this was then a wish-fulfilment; but with it came something like a compensation, something like a feeling of guilt arose and she became stirred up, substituted electricity for sexual sensations, and the whole picture was then made up of these sensations, - of a 
certain excitement, a feeling of danger with warning voices, the ideas of reference, the shunning of anything which recalled the main trend. In other words, the symptoms were largely grouped around the electrical sensations, while others, such as the hallucinations, "I love you," the seeing of the men, the appearance of the fog with the railroad train, the face, and the like, were phenomena parallel to the sexual sensations, but probably because they were not of such a disturbing character they remained comparatively in the background.

The second case is a woman thirty-six years of age, who even as a child was sensitive and stubborn; she often left the table on slight provocation, was hard to guide and influence, and was not inclined to confide in any one. She had a certain tendency to romanticism; liked literature and music, without, however, having any knowledge of either sufficient to give her a deep interest in them. Before her marriage her brother took her into his business as an assistant in the office, but she was inefficient, and yet constantly objected that she was not given better work to do. When twenty she married a cousin who was disliked by the family, and whom, it is thought, she herself really did not love. As a matter of fact she never got along well with him, and as marked evidence of this there stand out the following prominent features. In the first place she always made demands upon him which she knew he could not fulfill with his means; thus she wanted him to get a horse and carriage, and matters of that sort. It was not long after the marriage that another trait appeared which we also have reason to regard as a serious lack of adaptation, namely, her jealousy of him. This came out for the first time plainly during her first childbirth, when she suspected her husband of being in love with her nurse. Four years after her marriage she met a dentist who called her Miss instead of Mrs.; she did not correct him. He made a deep impression upon her, she felt that he was different from her husband, more sympathetic, that she could talk better to him; she became infatuated with him at the time, as she herself said later. She had another child, and the same nurse took care of her. She again got the idea that her husband was in love with this 
nurse. Nine years after marriage, five years after she met the dentist, she was pregnant with the third child, Mary. In the mean time the lack of adaptation to her husband had increased, and her affection for the dentist had become more marked, so much so that at that time, as was discovered later, she had various longings which were to play an important part in her psychosis. Her relations towards her husband did not improve, there were frequent scenes, and she continued to be suspicious of him, in regard not only to the nurse, but also to some other woman. For some years before the onset of the psychosis they had very little sexual relation with each other, and for three years it had been given up entirely.

In the fall of 1906 she suspected her husband of intimacy with an Italian girl who occasionally visited his shop, and when, in January, 1907, she saw this girl deposit some money in a bank she took this as a confirmatory evidence that her husband was intimate with her.

In June, 1907, she was invited to stay at her sister's house, while the latter was absent. There she read two books which made a considerable impression on her, because they seemed to her to fit her case; one was about a woman whose husband was unkind to her and gave her no money, who consequently thought of leaving him, but who, as the patient put it, remained at her post and died; she had a devoted friend who was true to her to the end. In another story she read of a man who lived a life of selfdenial to serve the wroman he loved, but whom he could not marry. She thought of herself as the heroine and of the dentist as the hero. Towards the end of June, and probably not by accident, she one Thursday went to see the dentist, and then while sitting in his chair a feeling of love came over her. It returned again at night, and then for a while every night, after she had gone to bed, and she masturbated repeatedly. Then it returned with special force, chiefly every Thursday night, and then the more marked symptoms of the psychosis arose. She began to feel the dentist's presence near her, and a feeling came over her as if she were again looking into his eyes, "a feeling of love and longing, a sensuous feeling," as she herself expressed it. She used to 
sit on the porch at night and sing all the love songs she knew. They came without effort. As this went on she could not put her mind on her work. In regard to this period the husband says that he noticed nothing except that she lay down a good deal, was somewhat absorbed, and once he heard her talk to herself. By the end of August paranoic ideas regarding her husband again appeared; she found a stopcock on the gas stove turned on, and suspected that her husband wanted to kill her and the children; she also believed he had put something into the oatmeal for the same purpose; she was not sure whether her husband had done this himself or whether an Italian had done it for him. Nothing further was noticed by her friends until September ro, when she suddenly proposed to go to California to visit her sister. In talking of this during the analysis she said that she thought getting away would help her to overcome the feeling for the dentist which had taken such a hold of her. This plan was refused, but she repeated the same proposal a few days later, and at the same time made an attempt to again straighten out her relationship to her husband. She confessed to him that she had been in love with the dentist for thirteen years, and asked him for forgiveness. He rebuked her, and he, as well as the other members of the family, said it was too expensive to go to California. Next day the condition changed. She said that she was "in a muddle"; began to talk in a disconnected manner of things which were not understood by those about her. What is remembered of it is the following: she spoke of having kissed the old family doctor, of white pills which he had given her; she thought somehow some harm was done; she spoke of a murder committed by an Italian years before. She became religious, said she wanted to do what was right, wanted to bring all together and take them to church; she spoke, in this connection quite irrelevantly, of gauze shirts, thought the dentist was one Alexander, a former friend of the family; again thought she saw the dentist in various other persons.

When first observed the patient appeared oriented, but later said for a time she thought she was among the Blue Alsatian Mountains. She was nervous, uneasy, anxious to talk. She said at once, quite irrelevantly, that her family 
physician had given her large white pills during her childbirth; she made other remarks about the subject of childbirth, not only of her own, but also of that of her sister, and when asked why she said all these things, she answered, "It seems to be in my mind as though there was some connection." When questioned what this connection was, she said that the doctor also took care of her husband while he had appendicitis, that he told her he could not say what the outcome. would be, and, after the husband was saved, he asked her to kiss him; she added: "The thought comes to me that the baby resembled the nurse who took care of him - is such a thing possible?" When told that this was nonsense, she said, "But why does the thought come to me?" During the rest of the day she became more excited, kept breathing very deeply, would not keep on any clothes, slapped herself vigorously, and became very forced in her attempts at breathing.

Next day she said that she felt forced to breathe deeper and deeper, that she could not stop, that a feeling came over her as if she were paralyzed, and that she had to slap herself; again she said that she could not move her hands from her side and felt like a post. She also spoke of having heard people talk about a court, said she was afraid Mary was dead, "Perhaps some one might have given her something wrong." In answer to the question why she was so uneasy, she said that she ought to have told her husband about her sensations which she had at the dentist's, yet when asked what sensations, she mentioned a toothache.

On the third day she became more quiet and rational, and remained so for two weeks; various symptoms were present, certain ideas of reference, a certain uneasiness about the court. The latter she associated with the dentist. Perhaps he might have given her child something which harmed her and he might now be prosecuted by the law; she spoke of the dentist testing her in some way. Above all there was present a constant desire to see her children, especially Mary. She repeatedly thought the children were in the next house and tried to get to them; she often tried to run away and could in no way be reasoned with regarding this desire to see her children. The idea came to her that 
perhaps in some way she might have harmed the old family doctor. Then another excitement appeared, but without such markedly forced or odd actions. It seemed merely to be a constant senseless desire to get away to her children, with violent attacks upon the nurses when they would not open the doors, and, associated with this, was a constant insistence on following the examiner whom she finally half identified with the dentist,.or called by the name of her husband. After six or seven days she again quieted down, but was no longer accessible for further analysis. One could not get beyond such statements as that she was nervous because she wanted to see her children and the like. She was then taken home by her family, having, so far as could be ascertained, no definite delusions at that time. At home she took, quite contrary to her usual habit, exceptionally good care of the household, but at the same time dressed with great care, bought clothes beyond her means, surprised the family by denying that she had been in a hospital and by denying that the house had been sold to her brother. The latter had been done in order to raise some money, and the patient herself had attached her signature to the deed. After a month at home the patient was sent on a trip to California to visit a sister, accompanied by her brother. While she did fairly well at first, her condition soon became worse and she had to be sent to a hospital in California, where she still is a patient, nearly three years after the onset.

While we have thus far become acquainted with the superficial facts of the psychosis, we shall now have to add the results of the analysis and the interpretations derived therefrom. Here again, as in the last case, a special set of symptoms gave the key to the situation. As there it was the electrical sensations, so it was here the peculiar breathing and slapping, etc., the analysis of which led us back to an occurrence nine years before, namely, to the time when she was pregnant and when the birth of her daughter Mary occurred. Her husband was ill with appendicitis towards the latter part of her pregnancy, and as the relationship between the two at the time was strained and her longing for the dentist again had swept over her, she wished that he might not recover, when the family physician told her that 
he was in danger. She felt that then her chances for marrying the dentist would be better; that the dentist was already married throws an interesting light upon her personality, upon the lack of adaptation of her desires to reality, or perhaps upon that peculiar inadequate way in which dementia præcox personalities apply their libido. The husband got well, and when he was out of danger the old family physician asked her to kiss him for having saved him. "Then the childbirth came and a similar train of thought occurred. She hoped the child would not be born alive, because her chances for marrying the dentist would be less with three than with two children. The physician told her that there was some danger and that her pains were inadequate, and that it was necessary for her to exert herself, to bear down, to breathe deeply, and he gave her white quinine pills to increase her labor pains. She did not follow his directions adequately, as they did not meet with her own desire, but the child was born and grew up a healthy girl.

The elements of this episode which are here put together in a connected story we find again in a disconnected manner in her psychosis. This episode may well have stood in her mind as the symbol of her desire to get away from the husband and to marry the dentist.

After she had for several years virtually broken off her relationship with her husband and was beginning again to apply her love to some one else, it was this older part of the same trend which again came up; she was now compensating for her lack of exertion at the time, with the forced straining, slapping, beating herself, etc.; yet the opposite was not lacking, she feared that Mary might be dead. We know now that such fears represent very often repressed wishes. So that again there was on the one hand the assertion of her desire to have the child dead, and on the other hand a compensation for this desire. It is not improbable that the feeling which at times came over her, namely, that in spite of the slapping and breathing there was something like a paralysis, may have stood as a symbol for the child's death, just as at the time of the birth the lack of exertion stood for it. Of a similar nature is possibly her thought that Mary looked like the nurse, in other words, was not her 
child. Her speaking irrelevantly about an actual murder in the neighborhood by an Italian some years ago probably had some connection with her husband, whom she suspected of being in love with an Italian girl. It must be remembered that later she suspected her husband of wishing to kill her and doing it through an Italian; we know that such suspicions are often projected wishes. The feeling of guilt in regard to the child liberated as another compensation the idea about the court, which was quite prominent at times, and the general idea that some wrong had been done. It is certainly interesting that she projected her guilt on the dentist, thought that perhaps he had done something to Mary, and that there was going to be a court proceeding about him. Then the general uneasiness was attributed, not to the real source, but to such trivial substitutive matters as her kissing the old family physician, or her not having told her husband about her toothache. The idea that the dentist was testing her in some way may have been a part of that peculiar paranoic tendency which we often find in such cases where some sort of a relationship is imagined, instead of the desired one, often of a persecutory nature. Quite clear as a form of compensation or atonement is the patient's constant desire to see her children, especially Mary, which became at times very insistent and impulsive and dominated the clinical picture for a while. Of interest is also the delusion about Alexander. This Alexander was a childhood love of the patient. She said that she had often connected the two, the dentist and Alexander, because their eyes were so much alike, and it is possible that she fell in love with the dentist because of this fact. When asked what satisfaction it could possibly give to her to identify the dentist with Alexander, she said, with that insight which we find at times in our analyses, that then the dentist would not be married, because Alexander was not married; that she later connected the examiner with the dentist and with her husband was an instance of that typical diffuse application of the libido which we see in dementia præcox so often.

The religiousness which was present in the early part of the psychosis is a frequent form of compensation. She wanted to go to church; she said again and again that she 
wanted to do what was right; she wanted to take others to church, spoke of wishing to unite every one, all of which is along the line of the same desire for a moral readjustment. It was at this time that a peculiarly irrelevant utterance about a gauze shirt frequently appeared. When the patient was probed about the significance of gauze shirts it was found that in June when she went to the dentist it was very hot and she did not change her clothes, more especially her gauze shirt, and she felt that the dentist might perceive an odor. Why this came out at the time I do not know, but it is clear that it belongs to the same general trend.

If we now summarize this case we find that we have a woman who was somewhat of a shut-in personality, inasmuch as she was not easily influenced by her environment and was unable to adjust herself well. Throughout her married life there was a marked lack of adaptation to her husband, showing itself in demands which she made upon him and which she knew he could not fulfil, but also in her jealousy of him. This lack of adaptation finally found its expression in the cessation of intercourse. Long before this her longing for another man manifested itself, and when the husband was ill she wished he would die, and when her childbirth occurred, that the child would not be born, so that her chances to marry the other man would be greater, and consequently she refused to help in the birth; all this, in face of the fact that the other man was married. Later there followed some years of a virtual separation from her husband, during which there was no other outlet for her interest, for she was not specially fond of her children, and had not much social intercourse with any one else; and preceding the outbreak of the disease there was a period of inactivity and day-dreaming. During this period she went to see the dentist often, fell in love with him, her day-dreaming about him increased, and then more marked symptoms appeared, namely, the semi-automatic singing of love songs, the feeling of his presence, and a greater absorption. This was followed by renewed suspicions of her husband, she thought he wanted to kill her. After this we find an interesting effort towards a frank readjustment, her confessing to her husband, an attempt at making up with him, and a desire 
to get away from the dentist. When she was repulsed in both these directions there was almost at once a change, and the more acute breakdown came on, in which the picture was no longer clear, but in which the same trend prevailed, namely, that of her relationship to her husband, her desire to get away from him, to have fewer children, to marry the dentist, but in the foreground were the compensatory elements, as we have described in the analysis. The individual symptoms were: disconnected talk and incomprehensible actions, her speaking of white pills, of childbirth, of the family doctor, of having hurt him by kissing him, of the court, of her feeling guilty for not having spoken to her husband about the toothache, her fear about Mary's life, her constant desire to see her children, her peculiar actions of breathing and slapping herself, as well as her feeling paralyzed, her ideas that the dentist was testing her, that he was really Alexander, the idea that the dentist may have given something to Mary to hurt her, then her irrelevant talk of gauze shirts. All of these acts and ideas which appeared wholly disconnected and fragmentary, and entirely unaccounted for by anything which we could at first observe, belong to the same trend of ideas, directly connected with the sexual life in which there had existed conflicts for years prior to the onset of the psychosis. It is rather interesting that the patient herself said that she did not know what her ideas meant, but had a feeling, as she expressed it in the analysis, that there was some connection.

We may now supplement the report of these cases by a description and summing up of the most obvious mental mechanisms found in this disorder.

In the first place we find always the mechanism of wish fulfilment. In Case I this existed in the idea of the patient that she was married, in the hallucination of sexual sensations, and in the voice which said, "I love you," etc.; in Case II, in the presence of the dentist which the patient felt, in the identification of the dentist with Alexander, and in the idea that the child looked like the nurse. In some instances coitus is represented in hallucinations. One patient had a vision of her own marriage; another constantly heard her lover call "come"; a third patient heard that 
the wife of the man towards whom her longings went was to be killed.

Akin to this mechanism is the fact that many patients see the object of their longings in all sorts of persons, although this may have a somewhat different significance as well. A very excellent example of a complicated, deliriumlike wish fulfilment is given in Jung's article on the content of the psychosis.

On the other hand, Case I also covered up her wish fulfilment, that is to say she called that which we ultimately found to be plain sexual sensations "electrical influences," and she not only used that term metaphorically, but she dealt with them as such and believed them to be electrical. Here we see at work a force different from the wish fulfilment, something akin to a feeling of guilt and a desire to compensate for it. It is this compensation which represents another very important and very frequent type of mechanism. Quite often the compensation is in the direction in which the normal person compensates when the feeling of guilt is present, namely, in the direction of religion. In milder or early cases we find then greater interest in religion, in more advanced ones persistent praying, or, as I saw in one instance, the constant stereotyped repetition of a part of the Creed. Definite delusions which have this origin also frequently exist, the patient is "the only one free from original sin," is the "Virgin Mary," "St. Ann"; hears God say, "You are my beloved child," and sees herself go to heaven. One patient, who had fallen in love with a priest, had the idea of a peculiar mystical union of the priest, her husband, and Christ. Such vague ideas are not rare. It is quite possible that a conception of compensation which involves the idea of guilt is not always the correct formulation, but that somehow the undoing of that which a part of the personality desires may have its origin in an opposing force which cannot be thus expressed, and which has its root in the lack of sexual adaptation and the peculiar personality in general. This seems to be the view of Jung and Abraham. In hysteria similar opposing forces are found, but there it seems the feeling of guilt is more often a definite link or determining factor.

Something akin to compensation is to be found in the 
anxiety or uneasiness which we sometimes find associated with wish fulfilment, as in Case I, or in the case who suddenly got much frightened when she thought her husband had been killed by a priest after she had fallen in love with a priest. Or in Case II, who was stirred up by the idea that her child might be dead.

This leads us over to a type of compensation which we may call paranoid, inasmuch as it manifests itself in ideas of persecution. Here it represents the direct undoing, as it were, of the fulfilment of the wish. This is the case where we have the belief in the love of a certain person, and at the same time the persecution by that person. A girl hears a man say that he wants to marry her, but also that he wants to shoot her; or another patient, who believes that a man is in love with her, also insists that he is persecuting her. In such instances the patients are apt to push the ideas of persecution to the foreground, and we only find later that the opposite is peculiarly intermingled with it. All this shows how closely delusions of persecution may be related to wish fulfilments, and may explain some purely persecutory ideas.

We might speak of mechanism of atonement as another type of compensating mechanisms; as, for example, in the patient who had been sexually excited by seeing certain things, and who later had a persistent impulse to dig out her eyes; or in the more complicated instance furnished by Case II, where the patient made up for her lack of exertion during childbirth by vigorously breathing and slapping herself.

An interesting mechanism which leads us from these compensations to that which is called the negativistic mechanism is to be found in the shunning of anything which tends to bring up the main trend, the sort of thing which Freud has illustrated in his psychopa thology of every-day life. This is the case, for example, where the patient refuses to pass her urine, to sit down, to eat, or go to bed, because all this associated in her mind with her special difficulties; here may also be mentioned the substitution of trivial things for the important ones, as is the case when our second patient blamed herself for kissing the family physician, or for not having spoken to her husband about her toothache. 
We must further mention that peculiar rather gross tendency to shut out the environment by warding off any interference,- that which is called negativism, which we may see in a more active form when the pat ent may entirely refuse to have anything to do with the examiner; or which accounts for the persistent closing of the eyes, the shutting out of the outside world, and probably to a considerable extent for the marked so-called negativistic stupor.

We must finally mention in this connection that frequently symbols are used very much as in dreams. Much of that which is incomprehensible, particularly in some of the advanced cases, is due to the fact that we do not understand the symbols, as has been so well illustrated by Jung and Maeder.

If we now glance over the entire field of these data and attempt to see their significance and their laws, we find that these laws are not essentially different from those of normal, mental life.

From a general psychological point of view we may say that all our memories are grouped, as it were, in more or less extensive and more or less circumscribed complexes, in the formation and cohesion of which special interests take an important part. We might, perhaps, more correctly call the complexes centers of attraction. We can conceive of the mind, therefore, as made up essentially of trends of interest. In the course of individual development certain main tendencies of the personality develop, which then take the lead, while other tendencies become repressed. These repressed trends exert, nevertheless, a marked influence on the conscious thought and activity, as Freud has shown, but in normal life they do so mainly through the fact that the energy they supply is led into profitable channels. Every trend naturally pushes towards a realization in the direction of its feelings. If this is in harmony with the main tendencies of the personality this is useful and represents the dynamic force behind our thinking, and our pursu ts adapted to the environment and the given situation. If, however, trends which are not in harmony with the main tendencies of the personality, and which are, therefore, under the influence of repression, no longer find an outlet in profitable 
channels, but assume a more or less independent dominating role, it is not to be supposed that the laws which govern normal mental activity should be suspended; on the contrary, we shall expect to find the same principle of the trend pushing towards its realization, while at the same time the other tendencies of the personality assert themselves in repressing influences as well as in adjustment reactions, but owing to the disturbance of balance between the usurping trend and the main tendencies of the personality, the thinking and acting is then no longer adapted to the actual situation, but appears as something strik ngly out of contact with it, and is of a simpler and cruder type.

This, in so far as the mental side is concerned, is what seems to take place in the cases of dementia præcox, which can be analyzed; the overgrowth of certain trends at the expense of the main, well-adapted interests of the personality. 